\title{
A Game Study on Accounts Receivable Financing in Energy Conservation and Environmental Protection Manufacturing Supply Chain under Green Development
}

\author{
Gang Zeng ${ }^{1,2 *}$, Chengxuan Geng ${ }^{1 * *}$ \\ ${ }^{1}$ School of Economics and Management, Nanjing University of Aeronautics and Astronautics, \\ Nanjing 211106, P.R. China \\ ${ }^{2}$ School of Transportation Science and Engineering, Civil Aviation University of China, \\ Tianjin 300300, P.R. China
}

Received: 26 July 2021

Accepted: 13 September 2021

\begin{abstract}
In order to cope with the increasingly severe energy crisis and climate and environmental change, energy conservation and environmental protection industry has become an emerging field for the optimization of China's economic structure and the development of green circular economy. However, lack of funds restricts the growth of energy conservation and environmental protection industries. Aiming at the financing difficulty of energy conservation and environmental protection industry, this paper introduces supply chain finance theory and game theory to establish accounts receivable game model. In a two-level supply chain composed of the core manufacturer and the supplier with financial constraints, the optimal decision and profit of the supplier, manufacturer, and bank under the condition of three-party compliance are studied, by using the Stackelberg game model. At the same time, the supply chain financing game under complete information condition and incomplete information condition is analyzed theoretically. Finally, through the method of example analysis, it is proved that the supplier's initial capital, the manufacturer's order quantity, the bank interest rate, the supplier's financing pledge rate and so on have a significant impact on the supply chain financing income.
\end{abstract}

Keywords: green development, energy saving and environmental protection, accounts receivable, financing, game

*e-mail: gzeng666@foxmail.com

**e-mail: gengchengxuan@126.com 


\section{Introduction}

In order to cope with the increasingly severe energy crisis and climate and environmental change, to vigorously develop the energy conservation and environmental protection industry has become an important direction of China's economic transformation. With the acceleration of industrialization and urbanization, China's energy supply and demand are severely unbalanced and the energy consumption is also unbalanced. In 2017, China's total energy consumption was 4,485,291,000 tons of standard Coal, and the Statistical Difference was -2,522.28, among which the balance of Raw Coal was -2,707.24. At the same time, China is a major emitter of carbon dioxide. As shown in Fig. 1, from 2009 to 2017, the energy consumption of chemical raw materials and chemical products manufacturing industry, metal products industry, non-metallic mineral products industry, rubber and plastic products industry all realized positive growth, increasing from 17,580, 12,043, 3,541 and 1,641 to $243,667,22,157$ and 21.75 million tons of standard coal respectively. Energy consumption and ecological imbalance restrict economic development. The fundamental way to solve the contradiction is to transform the traditional industrial structure and to develop energy-saving economy.

In 2021, the Chinese government set the goal of "striving to reach the peak of carbon dioxide emissions by 2030 and striving to achieve carbon neutrality by 2060" and vigorously promoted the development of low-carbon and green industries. According to the Comprehensive Work Plan on Energy Conservation and Emissions Reduction during the $13^{\text {th }}$ Five-Year Plan Period, by 2020, China's energy consumption per 10,000 yuan of GDP will be 15 percent lower than that of 2015 , and total energy consumption will be controlled within 5 billion tons of standard coal. China's total emissions of chemical oxygen demand, ammonia nitrogen, sulfur dioxide and nitrogen oxide will be kept within 2001 million tons, 2.07 million tons, 15.8 million tons and 15.74 million tons respectively, down 10 percent, 10 percent, 15 percent and 15 percent than those of 2015, respectively. The total emissions of volatile organic compounds (VOCs) in China decreased by more than 10 percent from that in 2015. As shown in Figure 1.1, in order to promote green, circular and lowcarbon development, the Chinese government has set specific COD emission control targets for all provinces. From 2015 to 2020, Zhejiang, Hebei and Henan have the highest emission reduction targets, reducing by $19.2 \%$, $19 \%$ and $18.4 \%$ respectively. Ningxia, Qinghai and Guangxi have the lowest emission reduction indexes, reducing $0.1,0.07$ and $0.3,500$ tons respectively.

In order to accelerate the cultivation of energy conservation and environmental protection industries and enhance green competitiveness, China has accelerated the development of energy conservation and environmental protection industries into pillar industries. In 2016, the $13^{\text {th }}$ Five-Year Plan for the Development of Energy Conservation and Environmental Protection Industry clearly proposed to build more than 100 key enterprises in four years, and to build 20 energy conservation and environmental protection industry cluster zones. The development of energy conservation and environmental protection industry cannot be separated from the support of funds, especially the enterprises in the initial stage of the industrial life cycle. The lack of funds directly affects the R\&D, operation and investment activities of the industry. Therefore, this paper mainly studies how to overcome the problem of insufficient financing in energy-saving and environment-friendly manufacturing industries, and analyzes the balance strategy between banks and enterprises from the perspective of game.

Energy conservation and environmental protection manufacturing financing involves the game between enterprises and investment subjects. Problems such as

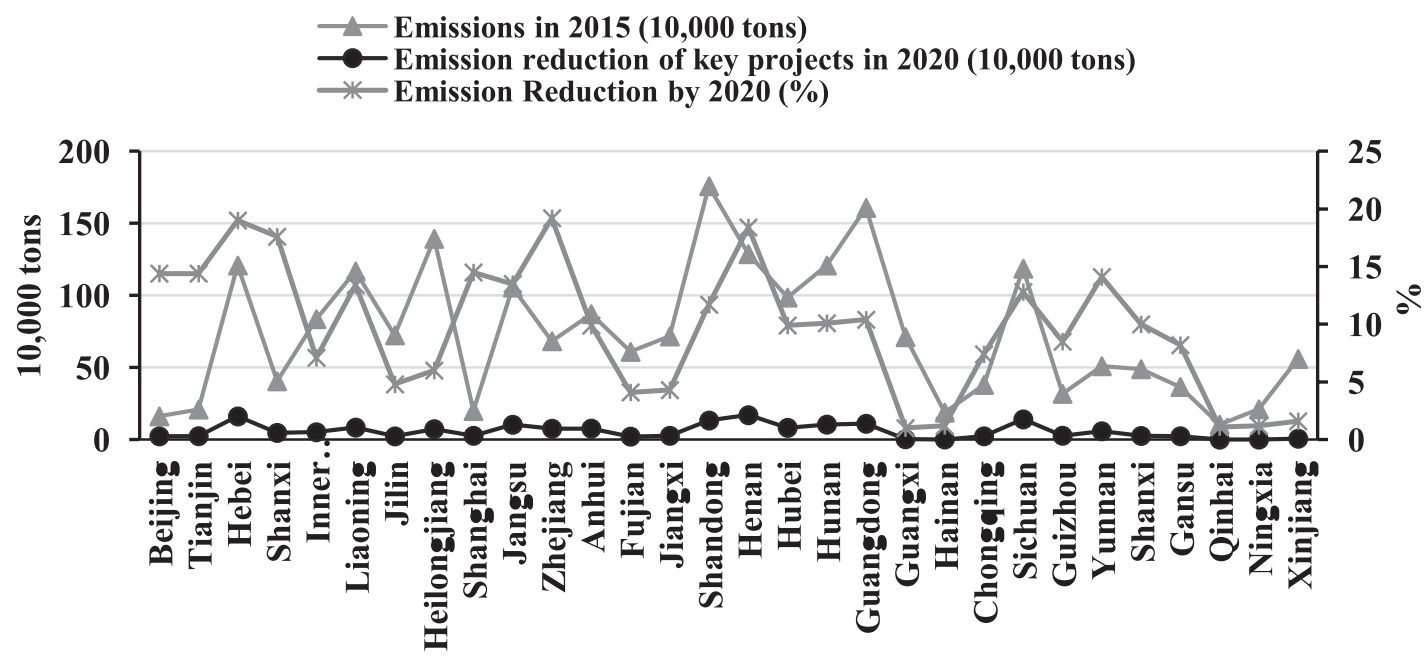

Fig. 1. Total COD emission control plan of major provinces in China during the $13^{\text {th }}$ Five-Year Plan period.

Note: Data of Tibet, Hong Kong, Macao and Taiwan is not included, due to data missing 
information asymmetry, adverse selection and moral hazard lead to financing difficulties for enterprises. [1] The financing game between enterprises and banks and other financial departments has already included the traditional bank-enterprise game and the emerging supply chain financing game, and the specific methods include the evolutionary game, signal game, Stackelberg game, supply chain financing game and so on $[2,6]$.

Research outside of China on the theory and application of financing game method is rich. In order to reduce information asymmetry, it is of great value to study the method of signal transmission to the outside world. Liu W. believe that the equilibrium state of the signal game of small and medium-sized enterprises depended on the signal cost, the mortgage terms of the bank, the repayment probability and other factors.[7] Kim J., Wagman L. believe that in a competitive market, whether angel investment and venture investors follow suit or not is influenced by the negative signals of the market. [8] In addition to the research on individual game, there are also some researches on group game process through evolutionary game method. Li S. established an evolutionary game model and found that investment risk and interest rate risk usually affect the decisions of venture capital firms, while internal governance risk is often difficult to change their investment decisions. [9] Evstigneev L., Hens T. built a dynamic stochastic equilibrium model of asset market based on the theoretical framework theory of non-traditional game, which combines the elements of stochastic dynamic game and evolutionary game [10].

In addition, there are also some studies on financing benefit sharing, random coordination, investment portfolio, green finance and other aspects. El F.A., Fairchild R., Tkiouat M. used game theory as a decisionmaking tool to construct a mixed profit-and-loss sharing model based on interest-free debt and equity financing. [11] Gerber A., Hens T., Vogt B. studied rational investor sentiment in repeated random coordination games with imperfect public monitoring, and found that quantitative technical analysis is a common investment tool based on experimental evidence. [12] Bellov S., V. Evstigneev I. studied Nash equilibrium strategy and survival portfolio rules in the evolution model of asset market. [13] Cui H, Wang R, Wang H. used the evolutionary game model to analyze the equilibrium strategy and influence mechanism of the government, financial institutions, enterprises and consumers on the changes in the green financial market. [14] These studies provide a lot of evidence to expand the theory and practice of financing game.

Since 2003, scholars in China have gradually paid attention to the game of enterprise financing, and these studies have gradually shifted their focus from the traditional bank-enterprise financing game to the supply chain financing game. An S., Zhou Y., Zhao Z. analyze how venture enterprises determine appropriate rate of return to optimize financing structure under the state of separation equilibrium. [15] In view of the "double high" phenomenon in the capital market, Dai L. analyzes the game between banks and enterprises under the condition of incomplete information, and divides the game process into two stages: borrowing and repaying. [16] These studies mainly focus on the two-party game, and some further studies also focus on the game behavior of the government and other intermediate departments. Liu E., He J., Zhao W. established a tripartite game model composed of major shareholders, investors and government supervision agencies. They selected listed companies from 2007 to 2012 as samples and found that government supervision had an impact on different types of companies, indicating that the government had an important impact on resource allocation. [17] Wen X., Jiang H., Zhang H., Zhang H adopted Yang's game model to simulate the financing decisions of small and micro enterprises, banks and guarantee institutions under non-malicious default, and proposed that encouraging small and micro enterprises to stick to contracts and maintain cooperation is helpful to reduce the losses of game participants. [18] Zhao X., Bai Y., Ding L., Xue Y. put forward the evolution model of bank-enterprise-trading center to solve the problem of slow down the development of carbon asset pledge financing. [19] The above results explored and solved the financing difficulties of enterprises from different perspectives by introducing the government, guarantee institutions and trading centers as participants. Although there were differences in the methods and samples of these studies, most of them were based on the financing game analysis under the traditional credit model.

With the emergence of new technologies such as the Internet and artificial intelligence, it has become a new trend to overcome information asymmetry and improve financing efficiency through supply chain financing. At present, supply chain financing is a revolutionary hot research to solve the problem of enterprise financing difficulties. Supply chain financing will inject financial services into the enterprises with capital constraints and provide the capital needed by the industry, which has strong theoretical significance and broad application prospects for alleviating the financing difficulties of enterprises. [20] Supply chain financing is a single credit granting business carried out by financial institutions according to the real transaction and reputation of a specific business in the supply chain, which involves multiple levels of departments such as financiers, guarantors and financial institutions. Therefore, the equilibrium state of financing game among participants is a hot topic of research. According to the existing literature, the content involved includes procurement financing, equity financing, pledge financing, and accounts receivable financing, etc.

Huang H., Liu Q., Ye C., Chen X. discussed the tripartite financing game model composed of small and medium-sized enterprises, government procurement departments and banks, proving that the integration of blockchain technology into contract procurement 
can improve the accuracy of financing. [21] Fang L., Xia Y., Yang Y. studied the influence of the retailer's effort on the optimal decision of supply chain financing. [22] Zhang L., Hu H., Zhang D. analyzed the multisubject interest decision under the pledge financing of accounts receivable. According to the simulation results, it is found that the bank's credit interest rate, supervision cost and penalty for breach of contract have an important influence on the supply chain financing game. [23] Zheng Z., Bao X. proposed to establish bankenterprise financing game under accounts receivable mode and analyzed how to improve the efficiency of supply chain financing by increasing the inspection rate and setting up a reasonable punishment mechanism. [24] These studies provide important references for exploring the supply chain financing strategies under different modes.

In this paper, the financing difficulty of energysaving and environment-friendly manufacturing enterprises is considered. Starting with the supply chain accounts receivable financing, the equilibrium strategy between banks and enterprises is discussed by game theory. Through mathematical simulation, this paper analyzes different factors that affect the balance of financing game.

\section{Material and Methods}

This paper takes into consideration the energy conservation and environmental protection manufacturing supply chain system, including suppliers, manufacturers and banks, and manufacturers have pricing power; at the same time, in order to simplify the process, the suppliers are regarded as a unified whole and regarded as one. Suppose the manufacturer's raw material price is $\omega$, the manufactured product price is $p$, and the marginal cost of the product is $c$, where $p>\omega>c$. At the same time, the demand for products in the downstream market is subject to the random distribution characteristic, and $G(x)$ and $g(x)$ respectively represent the distribution function and probability density function. $g(x)>0$, and $G(x)$ is monotonically increasing and differentiable, with IGFR properties. All participants have a preference for profit maximization and risk neutrality.
The supply chain financing model depends on the multi-party relationship with stable business transactions. This paper considers the accounts receivable financing game among suppliers, manufacturers and banks with strong correlation. The basic process is as follows: First, the manufacturer's raw material order demand is $q$, and the unit cost is $c_{m}$. At this point, the supplier's contract receivables are determined as $c q$. Second, the supplier has an initial amount of capital $A$. Due to the shortage of funds, accounts receivable financing is adopted. According to the supplier's production plan, assuming that the bank's loan interest rate is $r$, in order to avoid risk, the initial collateral required by the bank is $\beta c q$, and the financing applied by the supplier to the bank is $(1+$ $\beta) c q-A$. Due to the actual market change, the actual purchase quantity of the manufacturer is $Q, G(Q)$ is the corresponding probability density function, $\overline{G(Q)}$ is the distribution function, and $\overline{G(} Q)=1-G(Q)$. Finally, the manufacturer delivers the product according to the market demand, the unit price of the product is $p$, the quantity is $q_{2}$, the marginal cost is $t$, and the total value of the product is $p \min \left\{x, q_{2}\right\}$. After the manufacturer has delivered the products and received the payment as scheduled, the manufacturer will directly pay the raw material payment to the bank, and the bank will deduct the principal and interest of the supplier's loan $(1+r)(c q-A)$. At the same time, the pledge will be rescinded and the financing will be completed.The specific financing model is shown in Fig. 2.

\section{Description of Symbols and Related Assumptions}

\section{Parameter Setting and Compliance Instructions}

On the basis of the existing studies, the relevant parameters involved in the modeling in this paper are shown in Table 1.

\section{Assumptions Related to the Study}

Hypothesis 1: Consider a secondary supply chain composed of suppliers and manufacturers, in which the manufacturer has a core position. Upstream suppliers, composed of multiple suppliers, are taken as a whole.

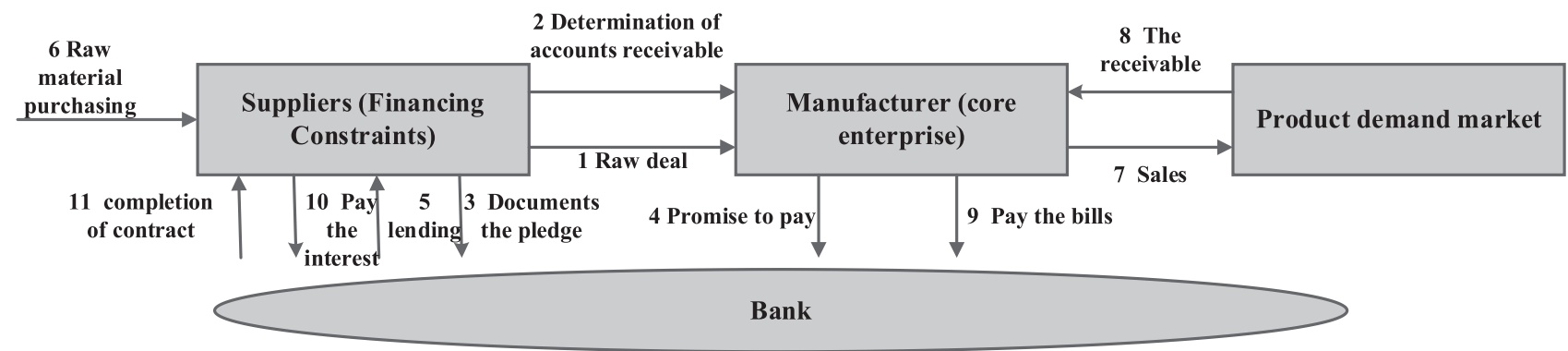

Fig. 2. Supply chain accounts receivable financing model. 
Table 1. Parameters and compliance instructions.

\begin{tabular}{|c|c|c|}
\hline The serial number & Symbol & The parameter name \\
\hline 1 & $p$ & The manufacturer's market price per unit product \\
\hline 2 & $c$ & Supplier's average cost per unit of production \\
\hline 3 & $c_{m}$ & Manufacturer's average cost per unit product \\
\hline 4 & $\omega$ & Wholesale prices for raw materials offered by a manufacturer to suppliers \\
\hline 5 & $q$ & The quantity of raw materials ordered by the manufacturer to the supplier \\
\hline 6 & $Q$ & Manufacturer's actual demand for raw materials from suppliers \\
\hline 7 & $r$ & The rate at which banks lend to suppliers \\
\hline 8 & $A$ & Supplier's initial capital \\
\hline 9 & $\varphi_{s}$ & Profit function of supplier \\
\hline 10 & $\varphi_{m}$ & Manufacturer's profit function \\
\hline 11 & $\varphi_{b}$ & The bank's profit function \\
\hline 12 & $x$ & Market demand for a manufacturer's product \\
\hline 13 & $g(x)$ & Manufacturer's product demand probability density function \\
\hline 14 & $G(x)$ & Manufacturer's product demand distribution function \\
\hline 15 & $T$ & At that time, the supplier through discount and other ways to recover the unit loss \\
\hline 16 & $\beta$ & $\begin{array}{c}\text { The percentage of the mortgage that the bank lends to the supplier based on the supplier's } \\
\text { production costs }\end{array}$ \\
\hline
\end{tabular}

In order to simplify the research process, these small and medium-sized suppliers are usually treated as a single supplier.

Hypothesis 2: Suppliers are constrained by funds. When funds are insufficient, only bank loan financing is considered. This paper considers that only one bank participates in the financing of accounts receivable in the supply chain. Manufacturers are flush with cash and have no need for financing.

Hypothesis 3: Participants pursue maximum returns and neutral risk.

Hypothesis 4: In supply chain financing, supply chain financing is in a state of complete information symmetry because suppliers and manufacturers have established a stable business relationship.

Hypothesis 5: The supplier's accounts receivable pledged to the bank requires factoring of accounts receivable, and the factoring fee is included in the bank's lending cost and adjusted through the loan interest rate $r$.

Hypothesis 6: $\omega>c+(1+\beta) r c>T \geq 0$

\section{Optimal Revenue Analysis when Three Parties Keep the Contract}

The paper considers the participant's maximum return target. Since the bank provides financing for suppliers with accounts receivable loans and core enterprises provide reverse guarantee for suppliers, the decision-making strategies for the three parties are suppliers (keeping promise: repayment, default: no repayment), manufacturers (keeping promise: guarantee, default: no guarantee) and banks (keeping promise: loan, default: no loan). The default of any of the three parties in the game will affect the development of the accounts receivable model of the supply chain. Therefore, the optimal return situation in the case of three parties keeping the contract is first taken into consideration.

Learning from Lu Q., Zeng L., Bao X. [25], Wang Z., Tian X., Chen X. [26], this paper adopts the reverse induction method to solve the problem: (1) The manufacturer determines the production plan and output according to the downstream market. (2) Due to the production needs, the manufacturer proposes the raw material demand to the supplier, and the supplier solves its optimal production decision based on capital, loan cost and other factors to pursue the maximum profit.

\section{The Supplier's Optimal Decision}

Suppliers $A$ with initial funds received orders $q$, and the actual production is $Q$. However, due to the lack of funds, suppliers use accounts receivable contract loans, and manufacturers are to guarantee.

Then, under the supplier's loan receivable financing mode, its profit function can be expressed as follows:

$\varphi_{s}=\omega \min (q, \lambda q)-c q-r[(1+b) c q-A]+T[Q-\min (q, Q)]^{+}$ 
In the above formula (1), $\omega \min (q, \lambda q)$ represents the paid-in payment of suppliers, $c q$ represents the total production cost, $r[(1+\beta) c q-A]$ represents the principal and interest of the bank, and $T[Q-\min (q, Q)]^{+}$represents the recovery value obtained by the supplier through discounting or low price sales in case of oversupply. If $q \geq Q$, then $T[Q-\min (q, Q)]^{+}=T(q-Q)$. If $q<Q$, then $T[Q-\min (q, Q)]^{+}=0$, that is, the raw materials produced by the supplier are fully supplied.

Then, the formula can be extended as:

$$
\varphi_{s}=\left\{\begin{array}{l}
\omega Q-c q-r[(1+\beta) c q-A]+T(q-Q), q \geq Q \\
\omega Q-c q-r[(1+\beta) c q-A], q<Q
\end{array} .\right.
$$

(1) When $A>c q$, that the supplier's initial capital is adequate is considered.

Supply chain operation can be realized by relying on endogenous funds, which is an ideal state, without the need to obtain funds through bank loans. At this point, the optimal yield of the supplier $q_{0}$ mainly depends on the actual product demand of the manufacturer. According to the simple newsboy model, the optimal yield of the supplier satisfies the formula (3):

$$
\bar{G}\left(q_{0}\right)=(c-T) / \omega-T .
$$

(2) When $\beta c q \leq A<c q$, that the supplier's initial capital is inadequate is considered.

The supplier was supposed to apply for loan(s) from the bank through supply chain financing, and it is considered that there was no risk of bankruptcy.

When $\beta c q \leq A<c q$, the supplier has the ability to make an initial margin payment to the bank, and to avoid bankruptcy, it is necessary to keep earnings positive.

According to (2), if and only when $\varphi_{s} \geq 0$, the supplier realizes positive income and has no risk of bankruptcy. At the same time, in order to realize the market demand $Q$, no matter how it changes, that is $q \leq q_{1}$, the supplier will not go bankrupt.

To solve the problem of the supplier's optimal return, it is necessary to solve $E \varphi>0$. According to the hypothesis and Equation (1), the value can be obtained as follows:

$$
q_{1}=\frac{A(1+r)}{c+r(1+\beta) c-T}
$$

At the same time, since suppliers need to borrow money from banks, it is easy to get:

$$
A<c q
$$

Therefore, the following numerology can be obtained:
Numerology 1: When $\beta c q \leq A<c q$, it is considered that the supplier has insufficient initial funds. The following conditions need to be met if the supplier is to be risk-free under any market conditions:

$$
\frac{A}{c}<q \leq \frac{A(1+r)}{c+r(1+\beta) c-T}
$$

Among them:

$$
0<\omega<(1+r+\beta r) c
$$

Corollary 1: when $\beta c q \leq A<c q$, the optimal solution $q_{2}$ of the objective function (1) satisfies

$$
\frac{A}{c}<q \leq \frac{A(1+r)}{c+r(1+\beta) c-T}
$$

and also

$$
\bar{G}\left(q_{2}\right)=\frac{c+(1+\beta) r c-T}{\omega-T}
$$

(3) Suppose the supplier's initial funds are insufficient and he need to borrow money from the bank, but the manufacturer's reduced demand for raw materials leads to the risk of bankruptcy.

When $\beta c q \leq A<c q$, suppliers resorted to loan financing. It is assumed that the critical point of the supplier's bankruptcy is $q_{3}$, that is, if the manufacturer's order quantity to the supplier is less than $q_{3}$, then the supplier will have negative income. The solution of $q_{3}$ can be obtained through the assumption conditions and Equation (1)

Then, as $q_{3}$ is the break-even point of the supplier, the following relationship can be obtained:

$$
(\omega-T) \bar{G}\left(q_{3}\right)=[c+(1+\beta) r c-T] \bar{G}\left[h\left(q_{3}\right)\right]
$$

Where $h\left(q_{3}\right)=\frac{c+(1+\beta) r c-T}{\omega-T} q_{3}-\frac{A(1+r)}{\omega-T}$, and $q_{3}$ is the solution of Equation (9).

Numerology 2: When the supplier's endogenous funding A meets the condition where $\beta \mathrm{c} q_{2} \leq A<\frac{c+(1+\beta) r c-T}{\omega-T} q_{3}$, then $q_{3}$ is the supplier's optimal production decision. Wherein, $q$ can be obtained by Equation (9). At the same time, as $\bar{G}\left(q_{2}\right)$ is a monotonically decreasing function, when $A=\frac{c+(1+\beta) r c-T}{\omega-T} q_{3}$, then $q_{2}=q_{3}$.

Proof: From Equations (1) and (9), we can get: 


$$
\begin{aligned}
& E \varphi_{3}=(\omega-T)\left[\int_{h\left(q_{3}\right)}^{q_{3}}\left(Q-h\left(q_{3}\right) d G\left(q_{3}\right)\right]+\int_{q_{3}}^{+\infty} \int_{h\left(q_{3}\right)}^{q_{3}}\left[q_{3}-h\left(q_{3}\right) d\left(G\left(q_{3}\right)\right)\right]\right. \\
& \frac{d E \varphi_{s}}{d q_{3}}=(\omega-T)\left[\bar{G}\left(q_{3}\right)-\frac{c+(1+\beta) r c-T}{(\omega-T)} G\left(\bar{h}\left(q_{3}\right)\right]\right.
\end{aligned}
$$

Therefore, in combination with Equation (9), it can be known that $q_{3}$ is an optimal solution to satisfy $\frac{d E \varphi_{s}}{d q}$.

In addition, since the actual raw material demand of the manufacturer $Q$ has IFR characteristics, therefore, when $Q=q_{3}$, we can get $\phi\left(q_{3}\right)>\phi\left(h\left(q_{3}\right)\right)$.

According to the analysis in 1.2 , the following inequality can be obtained:

$$
\frac{c+(1+\beta) r c-T}{\omega-T}<1
$$

So, when $Q=q_{3}$

$\frac{d E_{\varphi_{s}}^{2}}{d_{q_{3}}^{2}}=-[\omega-T] g\left(q_{3}\right)+\frac{[c+(1+\beta) r c-T]^{2}}{(\omega-T)} g\left(h\left(\bar{q}_{3}\right)\right)$

$\frac{d E_{\varphi_{s}}^{2}}{d_{q_{3}}^{2}}=-[c+(1+\beta) r c-T]\left[\phi\left(q_{3}\right) \bar{G}\left(h\left(q_{3}\right)\right)+\frac{c+(1+\beta) r c-T}{(\omega-T)} \phi\left(h\left(q_{3}\right)\right) \bar{G}\left(h\left(q_{3}\right)\right]\right.$

$\frac{d E_{\varphi_{s}}^{2}}{d_{q_{3}}^{2}}=-[c+(1+\beta) r c-T] \bar{G}\left(h\left(q_{3}\right)\right)\left[\phi\left(q_{3}\right)-\frac{c+(1+\beta) r c-T}{(\omega-T)} \phi\left(h\left(\bar{q}_{3}\right)\right)\right]$

Therefore, $\frac{d E_{\varphi_{s}}^{2}}{d_{q_{3}}^{2}}<0$, that is $\varphi_{\mathrm{s}}$ is the concave function, and $\varphi_{\mathrm{s}}$ is its optimal solution.

Finally, according to Equation (9) and the IFR characteristics of $Q$, the following relation can be obtained:

$$
\frac{d q_{3}(A)}{d A}=-\frac{(1+r) \phi\left(h\left(q_{3}\right)\right.}{(\omega-T) \phi\left(q_{3}\right)-[c+(1+\beta) r c-T] \phi\left(h\left(q_{3}\right)\right)}
$$

According to the assumptions:

$$
\begin{gathered}
(\omega-T)>[c+(1+\beta) r c-T]>0 \\
\phi\left(q_{3}\right)>\phi\left(h\left(q_{3}\right)\right)>0
\end{gathered}
$$

As a result,

$$
\frac{d q_{3}(A)}{d A}=-\frac{(1+r) \phi\left(h\left(q_{3}\right)\right.}{(\omega-T) \phi\left(q_{3}\right)-[c+(1+\beta) r c-T] \phi\left(h\left(q_{3}\right)\right)}<0
$$

Ergo, $q_{3}(A)$ is a minus function of the variable initial capital $A$. If the supplier's initial capital increase is to be realized when $A=\frac{c+r(1+\beta) c-T}{1+r} q_{3}$, the supplier does not have the risk of bankruptcy, then there is

$$
q_{3}=\frac{A(1+\mathrm{r})}{c+r(1+\beta) c-T}=q_{2}
$$

The proposition is proved.
(4) If $0<A<\beta c q$, the supplier is unable to pay the initial mortgage margin to the bank, thus leading to the supply chain financing failure. At this point, the supplier's optimal output is $q_{4}=0$.

According to the above analysis, due to the difference in the size of the initial capital of suppliers, there exist four situations concerning the probability of success through supply chain financing and the risk of bankruptcy. Combined with the actual situation, only when the supplier has enough endogenous funds for initial guarantee of supply chain financing, and there is no risk of bankruptcy, can the stable supply chain financing activities be carried out.

Therefore, when evaluating the optimal financing decision of the manufacturer and the bank, it is necessary to assume that the supplier has the initial capital, but it cannot meet the production needs, and initiates the financing loan to the bank without the risk of bankruptcy.

\section{Manufacturer's Optimal Decision}

According to 1.2 , the conditions for the supplier to finance through the supply chain without any risk of bankruptcy are as follows:

$$
\frac{A}{c}<q \leq \frac{A(1+r)}{c+r(1+\beta) c-T}
$$

So, the manufacturer's pre-order quantity to the supplier is $q$, but due to market changes, the actual demand order quantity is $Q, q$ and $Q$ may not be the same.

Therefore, the manufacturer's profit decision model is as follows:

$$
\begin{gathered}
\varphi_{m}=p x-\omega \min (q, Q)-c_{m} x \\
\varphi_{m}=\left\{\begin{array}{l}
P x-\omega Q-c_{m} x, \ldots \ldots \frac{A}{c}<Q \leq h\left(q_{3}\right) \\
P x-\omega q-c_{m} x, \ldots \ldots h\left(q_{3}\right)<Q \leq \frac{A(1+r)}{c+r(1+\beta) c-T} \\
\max _{Q} E \varphi_{m}=\int_{\frac{A}{C}}^{h\left(q_{3}\right)}\left(p x-\omega Q-c_{m} x\right) Q g(Q) d Q \\
+\int_{h\left(q_{3}\right)}^{\frac{A(1+r)}{c+r(1+\beta)-T}}\left(p x-\omega q-c_{m} x\right) Q g(Q) d Q
\end{array}\right.
\end{gathered}
$$

\section{Optimal Earnings of Banks}

Since we mainly consider the situation that the supplier has no bankruptcy risk, the optimal decision condition of the supplier is $\frac{A}{C}<q \leq \frac{A(1+r)}{c+r(1+\beta) c-T}$, then the bank's income function is:

$$
\varphi_{b}=r[(1+\beta) c q-A]
$$


Assuming that the bank's earnings change comes from the adjustment of interest rate $r$, the bank's optimal interest rate can be determined by the initial capital of the known supplier and the optimal order quantity of the manufacturer. The following is an analysis of how to determine the optimal interest rate when the supplier is in the condition of 1.3 .

Numeralog 2: When $\beta c q \leq A<c q$, the supplier borrowed money from the bank and there was no risk of bankruptcy. The return function of banks is (11).

Let us say $q=q_{3}$ is a solution to the equation $\omega-T-\frac{c-T}{G \overline{(q)}}=(\omega-T)\left(q_{3}-\frac{A \phi(q)}{(1+\beta) c}\right)$.

Then the bank's optimal interest rate is:

$$
r^{*}=\frac{(\omega-T) G(q)-(c-T)}{(1+\beta) c}
$$

Proof: According to 1.2, when the supplier lends money without risk, there is the following relationship:

$$
\bar{G}(q)=\frac{c+(1+\beta) r c-T}{\omega-T}
$$

Therefore, the relation of bank interest rate can be obtained by further deformation:

$$
r=\frac{(\omega-T) \bar{G}(q)-c+T}{(1+\beta) c}
$$

Substitute the value of $r$ into Equation (11), and the expected income of the bank can be obtained:

$$
\varphi_{b}=\frac{(\omega-T) \bar{G}(q)-c+T}{(1+\beta) c}[(1+\beta) c q-A]
$$

$\varphi_{b}$ the derivative of the first order $q$ can be obtained as follows:

$$
\frac{d E \varphi_{b}}{d_{q}}=\bar{G}(q)\left[(\omega-T)-\frac{c-T}{\bar{G}(q)}-(\omega-T) \phi(q)\left(q-\frac{A}{(1+\beta) c}\right)\right]
$$

According to the above analysis, $q_{2}$ is a solution to Equation (13). Because of the IFR properties, if we make

$$
h(q)=(\omega-T)-\frac{c-T}{\bar{G}(q)}-(\omega-T) \phi(q)\left(q-\frac{A}{(1+\beta) c}\right)
$$

$h(q)$ is the monotone decreasing function of $q$, where $h\left(q_{2}\right)=0$.

So, when $q=q_{2}$, the bank makes the most profit. Moreover, the bank's optimal interest rate is:

$$
r=\frac{(\omega-T) \bar{G}\left(q_{2}\right)-c+T}{(1+\beta) c}
$$

\section{Tripartite Game Analysis of Supply Chain Financing}

In the supply chain financing mode, due to some internal and external factors, banks, suppliers and manufacturers may violate the agreement and hinder the sustainable financing of the supply chain. In order to analyze the optimal decision of supply chain participants under the condition of Nash equilibrium under various uncertainties, this paper will introducing the game theory to analyze, referring to Peng H., Cao W. [27], Ma C. [28].

First, it is assumed that the order quantity of the manufacturer is equal to the supply quantity of the supplier, i.e $q=Q$. At the same time, the downstream market is in the peak trading season, the manufacturers' products can be fully sold, and the production volume of suppliers' products is equal to the market demand $\mathrm{x}$, and there are no inventory losses.

According to the related research and hypothesis above, in the energy-saving and environmental protection supply chain financing mode, the important basis for banks to make financing decisions is to evaluate the financial ability and reputation of the manufacturer in the core position, which is the key to the success of supply chain financing. Whether the manufacturer provides credit guarantee directly affects the bank's decision. In the financing process, the supplier finances with accounts receivable, while the bank requires certain collateral. After receiving the payment, the manufacturer will directly return the loan principal and interest of the supplier to the bank and settle the accounts with the supplier. In the event of a default, banks would claw back loans from suppliers and manufacturers.

Similarly, if the upstream supplier refuses to pay the interest on the financing, the bank can claim compensation from the manufacturer. Therefore, in the process of supply chain financing, the main body of the game-upstream suppliers, core manufacturers and banks-have two choices for whether to participate in the game: participate or not. The profit of supply chain is different due to the different decision-making of game players.

Specifically, the bank's decision is divided into two: to loan money or not. If the bank does not lend, then the game does not happen. Therefore, the premise that the bank is willing to lend is mainly considered. The manufacturer also has two choices: to guarantee (guarantee of the supplier's repayment and of the principal of accounts receivable on time) or no guarantee (no guarantee of repayment of loan and interest to the bank). If the manufacturer performs the contract, but the supplier defaults, the bank has no loss, the manufacturer will have the guaranteed loss of interest, and the supplier will suffer the penalty of loss of earnings and reputation. It can be assumed that in the supply chain financing mode, the supplier's income is $\varphi_{s}^{*}=\omega q-c q-r[(1+\beta) c q-A]$, and the loss caused 
by default is $\pi, \pi>0$. On the contrary, if the manufacturer breaches the contract and the supplier keeps the contract, the manufacturer will not pay the receivables $\omega q$ to the bank after receiving the payment, and the bank will suffer the loss of principal and interest. However, the profit of the manufacturer and the cost of breach include two parts: the profit from the breach is $\varphi^{*}=p x-c_{m} q$, and the penalty from the system is $Z, Z>0$. The supplier's loss is $\omega q$. Finally, if both the manufacturer and the supplier default, then the bank's loss on principal and interest is $\varphi^{*}{ }_{b}=(1+r)[(1+\beta)$ $c q-A]$. The supply chain financing fails, so the game subject cannot make profit, and at the same time the subject suffers punishment. The manufacturer's loss is $\left(\varphi_{m}^{*}+Z\right)=p x-\omega q-c_{m} q+Z$, and the supplier's loss is $\left(\varphi^{*}{ }_{m}+\pi\right)=\omega q-c q-r[(1+\beta) c q-A]+\pi$.

Then, the payoff matrix of the three parties of the game is shown in Table 4.

\section{Supply Chain Financing Game under Complete Information Condition}

In the case of a single game, $\pi=0, Z=0$. First of all, in the condition that the bank is willing to lend money, if the supplier defaults, for the manufacturer to take default measures can gain more profits, then the manufacturer's optimal decision is to default. The same if the supplier keeps the contract. Secondly, after the supplier gets the bank loan, since there is no default cost, if the supplier chooses to default, the supplier will get the excess return, and the increased earning is $(1+r)(\omega q-A)$. Finally, under the condition of complete information, the bank can predict all possible situations. To avoid possible bad debts, banks will reject suppliers' financing applications from the start of the game. Therefore, the equilibrium state of the bank, the manufacturer and the supplier is (to refuse the loan, to fail to keep the contract, and to fail to keep the contract), and the profit of the three parties is $(0,0,0)$.
In the factual situation, the probability of financing game appearing only once is low, and repeated game conforms to common sense. Because the players of the game all have the motivation to pursue the benefits of supply chain financing, the three parties of the game are willing to maintain the sustainability of supply chain financing by keeping the contract. Similar to what was mentioned above, first of all, in the case that the manufacturer keeps the contract, the supplier's income is analyzed. At this point, compliance and breach of contract affect the supplier's decision. The difference between the two is $M=\varphi^{*}-(1+r)(\omega q-A)=\omega q-r[(1$ $+\beta) c q-A]-(1+r)(\omega q-A)$, and if $M \geq 0$, then, the optimal decision of the supplier is to keep the contract; on the contrary, if $M<0$, then the suppliers are biased towards default.

Secondly, if the manufacturer defaults, then $M=\varphi^{*}$ $-(1+r)(\omega q-A)=\omega q-r[(1+\beta) c q-A]-(1+r)(\omega q-$ $A)$. In this case, if $M \geq 0$, the supplier keeps the contract; otherwise, defaults.

Then, the optimal decision of the supplier is to keep the contract. In any case, the assumption is $M<0$ that suppliers are biased towards default.

Therefore, if the supplier gains sufficient benefits through supply chain operations, i.e. $\gamma$ is large enough to make $M \geq 0$ permanent, then the supplier will give priority to strict compliance. Duo to complete information, the manufacturer is in control of the choice of suppliers. Thus, the choice of compliance strategy. The same to the above analysis, under the premise of supplier's compliance, the profit difference between the manufacturer's compliance and non-compliance is $N=\varphi^{*}{ }_{m}+Z-(\omega q-A)$. If $N \geq 0$, then the manufacturer chooses to keep the contract; if $N<0$, then the manufacturer chooses to default. Because $\left(\varphi^{*}{ }_{m}+A\right)>0$, if there is a constant situation where $Z-\omega q \geq 0$, that is, the manufacturer's loss of breach is large enough, the manufacturer abides.

Therefore, when $\gamma$ and $Z$ are large enough, that is, the supplier can get the maximum profit, and the

Table 4. Revenue Matrix.

\begin{tabular}{|c|c|c|c|}
\hline \multicolumn{2}{|c|}{ Bank } & \multicolumn{2}{|c|}{ Manufacturer (Core) } \\
\cline { 3 - 4 } & \multirow{3}{*}{ Keep the } & Keep the & Default \\
\cline { 3 - 4 } & & $p x-\omega q-c_{m} q$ & $-p x+c_{m} q-Z$ \\
\cline { 3 - 4 } Upstream Supplier & & $r[(1+\beta) c q-A]$ & $\beta c q-(1+r)[(1+\beta) c q-A]$ \\
\cline { 3 - 4 } & \multirow{3}{*}{ Default } & $\omega q-c q-r[(1+\beta) c q-A]$ & $-(1+\beta) c q$ \\
\cline { 3 - 4 } & & $p x-\omega q-c_{m} q-(1+r)[(1+\beta) c q-A]$ & $-p x+c_{m} q-Z$ \\
\cline { 3 - 4 } & & $r[(1+\beta) c q-A]$ & $\beta c q-(1+r)[(1+\beta) c q-A]$ \\
\hline & & $\omega q-c q+(1+r)[(1+\beta) c q-A]-\beta c q-\pi$ & $-(1+\beta) c q-\pi$ \\
\hline
\end{tabular}

Note: Suppose the bank agree to loan, $\pi$ is the supplier's penalty in case of default, and $Z$ the manufacturer's penalty in case of default 
manufacturer's default cost is high, then the bank inclines to issue the loan. Then, the equilibrium state of the bank, the manufacturer, and the supplier is to loan, to keep the contact, and to keep the contract.

\section{Supply Chain Financing Game under Incomplete Information}

In the factual situation, due to the interference of transaction link and external environment, information asymmetry between the game players of supply chain financing are prone to happen. The common situation is that the game players default due to external market changes. Therefore, it is necessary to analyze the financing game under the condition of incomplete information.

To control the risk, the bank will estimate the loan income. According to the above analysis, there are four states for the selection of suppliers and manufacturers: $R_{1}$ (repayment, repayment), $R_{2}$ (No repayment, repayment), $R_{3}$ (repayment, No repayment), $R_{4}$ (No repayment, No repayment). Assume that the probability of the manufacturer keeping the contract is $\delta_{1}$, and that of the supplier is $\delta_{2},\left(\delta_{1}, \delta_{2} \notin[0,1]\right)$, then the corresponding probabilities are $R_{1}, R_{2}, R_{3}, R_{4}$, and the respective possibilities are $\delta_{1} \delta_{2}\left(1-\delta_{1}\right) \delta_{2},\left(1-\delta_{2}\right) \delta_{1}$, and $\left(1-\delta_{1}\right)\left(1-\delta_{2}\right)$.

Then, the expectation of the bank's income under the supply chain financing game can be calculated: $E \varphi^{*}{ }_{B}$

$$
\begin{aligned}
E \varphi_{B}^{*}= & \delta_{1} \delta_{2} r(\omega q-A)+\left(1-\delta_{1}\right) \delta_{2} r(\omega q-A)-\delta_{1}\left(1-\delta_{2}\right) \\
& (\omega q-A)-\left(1-\delta_{1}\right)\left(1-\delta_{2}\right)(1+r)(\omega q-A)
\end{aligned}
$$

According to Equation (11), if $E \varphi^{*}{ }_{b}>0$, then the bank's expected income is larger than 0 , and the bank's loan is profitable. So, the game equilibrium strategy is (Loan, repayment, repayment). Therefore, to build a stable supply financing model, participants in the supply chain financing game are all motivated to keep their promise. In the repeated game process, the bank's choice to loan, the manufacturer's keeping its promise, and the supplier's repayment are in line with the interests of the three parties.

\section{Results and Discussion}

Supply chain financing is helpful to ease the financing pressure of capital constrained suppliers. The following analysis is mainly about the game equilibrium state under incomplete information, that is, the threeparty strategy (loan, repayment, repayment) and the change of supply chain income.

The energy-saving and environment-friendly manufacturing supply chain is mainly selected as a typical model, without considering transaction costs. At the same time, the product market demand is strong. In order to simplify the analysis process, it is assumed that the manufacturer's product order quantity is the same as the actual demand, that is $q=Q$, and the supplier's overproduction is not taken into account. The results of the relevant example analysis are as follows.

\section{Impact of Different Initial Funds and Interest Rates on the Earnings of Suppliers and Banks}

Because the manufacturer is in the core position and has pricing power, the changes of supply chain earnings when the wholesale price of raw materials changes and the bank adjusts interest rates are studied respectively. The specific results are shown in Table 5 and Fig. 3.

When the supplier has the same initial capital, the bank has the incentive to adjust the income through interest rate. When $A=5, c=1, q=10, \beta=0.1$, if the interest rate strategies adopted by the bank are $r=0.06,0.08,0.1$ respectively, the income of the supplier is $\varphi_{s}=9.64,9.52,9.4$ and the income of the bank is $\varphi_{B}=0.36,0.48,0.6$. Similarly, when $A=8$, $r=0.6,0.8,0.1$, the supplier's profit is $\varphi_{s}=9.82,9.76$, 9.7, and the bank's profit is $\varphi_{B}=0.18,0.24,0.3$. This shows that if the supply chain is stable, the bank can increase its income by increasing the interest rate. If the interest rates change, suppliers' and banks' earnings move in the opposite direction.

Different initial capital conditions need further analysis. When $\omega=6, c=1, q=10, r=0.1, \beta=0.1$, the initial capital $A$ increases from 2 to 6 , and the supplier and the bank's income both decrease, $\varphi_{s} \in[0.59,38.11], \varphi_{B} \in[0.51,0.89]$. When other parameters remain unchanged, make $\omega=9$, the trend of change is the same, $\varphi_{s} \in[30.28,67.58], \varphi_{B} \in[0.82,1.42]$. This shows that if the initial capital becomes larger,

Table 5. Impact of initial capital and interest rate changes on the supplier's earnings.

\begin{tabular}{|c|c|c|c|}
\hline $\begin{array}{c}\text { Initial } \\
\text { funding } A\end{array}$ & $\begin{array}{c}\text { Interest rate } \\
r\end{array}$ & $\begin{array}{c}\text { Supplier } \\
\text { revenue } \varphi_{s}\end{array}$ & $\begin{array}{c}\text { Bank returns } \\
\varphi_{B}\end{array}$ \\
\hline \multirow{4}{*}{5} & 0.06 & 9.64 & 0.36 \\
\cline { 2 - 4 } & 0.08 & 9.52 & 0.48 \\
\cline { 2 - 4 } & 0.1 & 9.4 & 0.6 \\
\hline \multirow{4}{*}{6} & 0.06 & 9.7 & 0.3 \\
\cline { 2 - 4 } & 0.08 & 9.6 & 0.4 \\
\cline { 2 - 4 } & 0.1 & 9.5 & 0.5 \\
\hline \multirow{4}{*}{7} & 0.06 & 9.76 & 0.24 \\
\cline { 2 - 4 } & 0.08 & 9.68 & 0.32 \\
\hline \multirow{4}{*}{8} & 0.1 & 9.6 & 0.4 \\
\cline { 2 - 4 } & 0.06 & 9.82 & 0.18 \\
\cline { 2 - 4 } & 0.08 & 9.76 & 0.24 \\
\hline
\end{tabular}


then the supplier's return will be diminishing, and the banks will change in line with it.

\section{Influence of Manufacturer's Order Quantity on Supply Chain Financing Income}

Assume that it is in the peak season of market demand, due to the change of the downstream market demand, the order quantity of the manufacturer to the supplier changes in the interval [2,10], and other parameters of supply chain financing are set as $c=1$, $r=0.1, A=1, \beta=0.1$.

As shown in Fig. 3 , if the three parties of the game keep the contract and $\omega=2$, when the manufacturer's order quantity $q$ increases from 2 to 10, the supplier's income $\varphi_{s}$ increases from 2.37 to 8.96 , and the change trend is $\uparrow$. The earnings of banks $\varphi_{B}$ increased from 0.131 to 0.946 , and the fluctuation trend was $\uparrow$. Similarly, in the case that the manufacturer's order quantity $q$ is within the range of 10 , when the wholesale price values are 3,5 and 8 respectively, the range of change of $\varphi_{s}$ is [4.47, 17.49], [8.67, 38.07], [14.96, 66.02].

From the trend analysis, if the order quantity increases, then the supplier's income will increase. Furthermore, the income direction of banks and suppliers is the same, both of which are positive growth, which verifies that supply chain financing is a win-win model.
This shows that in a system with a stable supply chain relationship, suppliers can alleviate the problem of insufficient funds and obtain positive benefits through the credit guarantee of the core manufacturer. And banks can get enough interest income and have enough incentive to continue to carry out supply chain financing. The results of a numerical example demonstrate the validity of the conclusion.

\section{Influence of Bank Interest Rate on Supply Chain Financing Income}

Under the hypothesis of rational economic man, the bank adjusts the income by dynamically adjusting the loan interest rate in order to pursue the maximum income.

Assume that the interest rate of the bank varies within $[0.06,0.25]$ and other parameters are set as $c=1$, $\omega=6, \beta=0.1, A=1$ or 2 , and then Fig. 4 is obtained.

As shown in Fig. 4, when other parameters remain unchanged, with the increase of bank interest rate, the supplier's income gradually decreases, while the bank's income gradually increases. When the initial capital $A=1$, if $r=0.6$, then the supplier's return $\varphi_{s}=15.51$, and the bank's return $\varphi_{B}$ is 0.49 . When interest rates increase $r=0.25, \varphi_{s}=13.93$, the bank's earnings increase $\varphi_{B}=2.75$. Similarly, when $A$ is adjusted to other values, and when the interest rate $r$ increases from 0.06
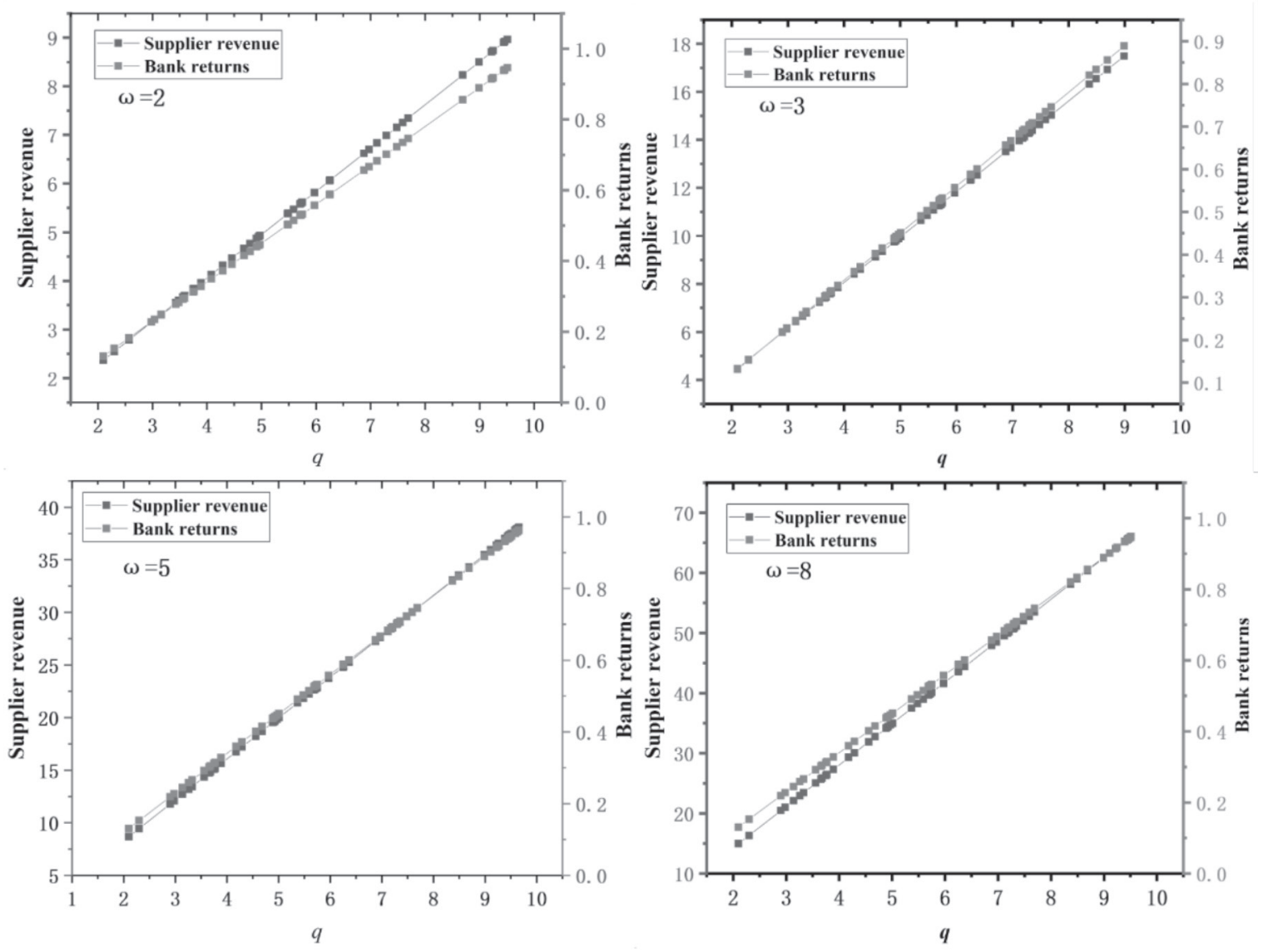

Fig. 3. Influence of different order quantities on the earnings of suppliers and of banks. 

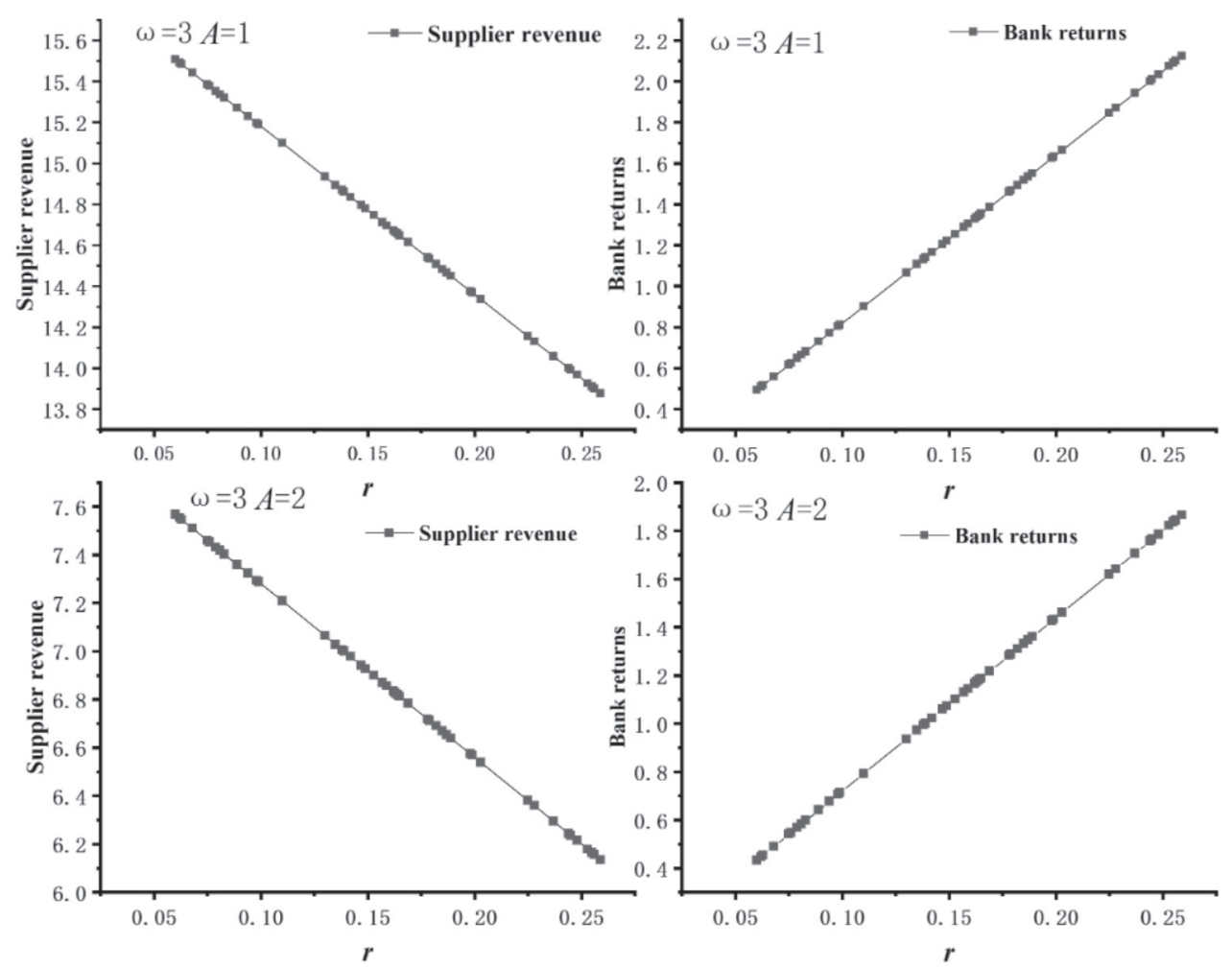

Fig. 4. Impact of bank interest rates on supplier and bank earnings.

to 0.25 , the supplier's income decreases from 7.57 to 6.18 , and the bank's income increases from 0.43 to 1.82 . The same research conclusion is obtained by changing the initial funding conditions, which indicates that the research is robust.

This fully shows that in the process of supply chain financing, for the sake of risk avoidance, banks will adjust the interest rate to achieve the optimal return. When the financing amount of the supplier is small, the risk of the bank is controllable and the loan interest rate is low. When suppliers raise large amounts of financing, banks will raise interest rates because of the risk of bad debts caused by suppliers defaulting. Therefore, within a certain range, through the interest rate adjustment
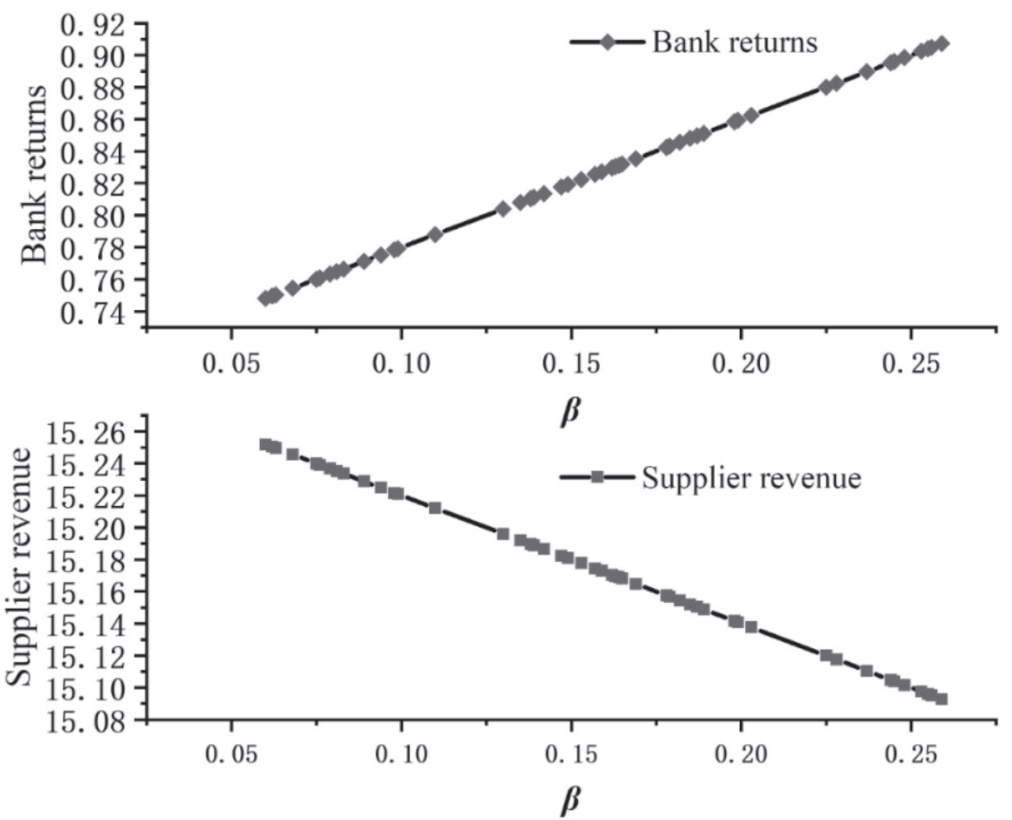

Fig. 5. Impact of pledge rate on supplier and bank earnings. 
mechanism, banks can avoid risks on the one hand and provide financing needs for suppliers on the other hand.

\section{Influence of Pledge Rate on Supply Chain Financing Income}

In order to reduce risks, the bank requires the supplier to pledge a certain proportion of the capital as the deposit according to the size of . Then, in order to analyze the impact of on the financing subjects of the supply chain, make $\omega=3, A=1, c=1, q=8, r=0.1$, $\beta \in[0.06,0.25]$, and Fig. 5 is obtained.

According to the results of numerical analysis, when $\beta=0.06$ and $\varphi_{s}=15.25, \beta=0.25, \varphi_{s}=15.10$. So the higher the pledge rate is, the lower the supplier's income is. On the contrary, when $\beta=0.06, \varphi_{B}=0.75$, the bank's profit is the lowest; when $\beta=0.025, \varphi_{B}=0.90$, the bank's profit is the highest. The higher the collateral ratio is, the greater the bank's profit is.

This indicates that in supply chain financing, by setting a certain pledge rate, the bank can constrain the compliance behavior of the supplier to a certain extent and obtain a certain income at the same time. In the actual process, only by setting a reasonable pledge rate can the bank reduce risks and the supplier can bear it. If the pledge rate is too large, the supplier will be unable to finance due to insufficient reserve funds; if the pledge rate is too small, it will be unable to play a restrictive role. Therefore, in the supply chain financing game, the pledge rate can also play a role in promoting the balance of financing game.

\section{Conclusions}

This paper selects accounts receivable financing model as a typical model, considers a two-level supply chain composed of the core manufacturer and the suppliers with capital constraints, and uses the Stackelberg game model to study the optimal decision and income of suppliers, manufacturers and banks under the condition of three parties keeping their contracts. Duo to the consideration that in reality, all decision-making participants may break the contract due to subjective or objective factors, the supply chain financing game under complete information condition and incomplete information condition are theoretically analyzed. Finally, through the method of example analysis, the supply chain financing model with stable relationship is established, and the influences of the initial capital of the supplier, the order quantity of the manufacturer, the bank interest rate and the financing pledge rate of the supplier on the financing income of the supply chain are tested. The conclusions of this study are as follows:

1. In a second-level supply chain composed of the manufacturer in the core position and the manufacturer with financing constraints, the risk of bankruptcy may occur in the financing of the supply chain through accounts receivable, and the optimal financing income of the financing participants is a process of repeated game.

2. For a mature supply chain, under the condition of complete information and incomplete information, the Nash equilibrium state of the game of bank, supplier and manufacturing financing is (loan, repayment, repayment).

3. In a stable supply chain, the three parties of the game strictly abide by the contract. Through the analysis of the calculation examples, it is found that when the initial capital amount of the supplier increases from the bottom to the top, the supplier's income and the bank's income show a decreasing change, that is, the larger the initial capital amount is, the smaller the supplier's income and the bank's income. With the increase of the order quantity of manufacturers, the supply chain financing income of suppliers and banks increases, and the fluctuation trend is $\uparrow$.

4. Banks have the motivation to avoid risks by adjusting interest rates and financing pledge rates. When the financing amount of the supplier is small, the bank will provide lower interest rate due to lower risk. When suppliers raise large amounts of financing, banks will raise interest rates because of the risk of bad debts caused by suppliers defaulting. By setting a certain pledge rate, the bank can constrain the supplier's compliance behavior to some extent and obtain a certain income at the same time.

\section{Acknowledgments}

This research was funded by general project of humanities and social sciences of Tian Jin education commission research program (No.2019SK103).

\section{Conflict of Interest}

The authors declare no conflict of interest.

\section{References}

1. LI L., GAO H., CHEN J. Signal Game Analysis of Credit Financing of China's High-tech Enterprises , Economic Research Journal, 50 (06), 162, 2015.

2. LIU H., LI B. Game Model of Signaling of Credit Information Sharing between Banks and Enterprises under Market Interest Rate Environment, Operations Research and Management, 24 (06), 205, 2015.

3. ZHAO X., BAI Y., DING L., XUE Y. Evolutionary Game of Financing for Verification Emission Reduction Pledge with Government Participation, Journal of Beijing Institute of Technology (Social Science Edition), 22 (01), 29, 2020.

4. YI X., ZHOU Z. Credit Decision Mechanism of Inventory Pledge Financing Bank Based on Dual Stackelberg Game, Systems Engineering, 29 (12), 1, 2011. 
5. LIU F., ZHAO Y., LIU W. Two-stage Financing Game of Enterprises under the Mechanism of Repeated Bet Agreement, Journal of System Management, 26 (03), 528, 2017.

6. ZHANG L. Research on Blockchain Driven Supply Chain Financial Innovation from the Perspective of Game Theory, Economic Issues (04), 48, 2019.

7. LIU W. Financing problem in small and medium-sized private enterprises, Journal of Finance \& Finance, 28 (3), 1218, 2017.

8. KIM J., WAGMAN L. Early Stage Entrepreneurial Financing: A Signaling Perspective, Journal of Banking \& Finance, 67 (7), 12, 2016.

9. LI S. Evolutionary Game Simulation of Corporate Investing and Financing Behavior from a Risk Perspective, Journal of Cluster Computing 22 (3), 219-220S5955-S5964, 2019.

10. EVSTIGNEEV L., HENS T. The equilibrium of equilibrium and evolutionary dynamics in asset markets, Journal of Mathematical Economics, 91 (12), 121, 2012.

11. EL F.A., FAIRCHILD R., TKIOUAT M. A hybrid profit and loss sharing model using interest free-debt and equity financing, North American Journal of Economics and Finance, 49 (7), 352, 2019.

12. GERBER A., HENS T., VOGT B. Rational Investor Sentiment in Multiple Stochastic Game with Imperfect Monitoring, Journal of Economic Behavior \& Organization, 76 (3), 669, 2010.

13. BELLOV S., EVSTIGNEEV V.I. Evolutionary Models for Asset Markets, Journal of Mathematics and Financial Economics, 14 (2), 249, 2010.

14. CUI H., WANG R., WANG H. An evolutionary analysis of green finance sustainability based on multi-agent game, Journal of Cleaner Production, 269 (10), 121799, 2020.

15. AN S., ZHOU Y., ZHAO Z. Research on Financing Strategy of Venture Firms Based on Dynamic Game Analysis of Incomplete Information, Journal of Quantitative and Technical Economics 10, 120, 2003.

16. DAI L. The Influence of "Double High" Phenomenon, Bank-Enterprise Game and Financing Environment of Transitional Economy, China Soft Science (02), 40, 2010.

17. LIU E., HE J., ZHAO W. Return to control, firm quality and financing instrument selection, PP. A three-way game analysis based on refinancing regulation, Journal of Sun
Yat-sen University (Social Science Edition), 54 (05), 185, 2014.

18. WEN X., JIANG H., ZHANG H., ZHANG H. Research on Trust Repair Strategies among Various Subactors in the Financing Guarantee Circle of Defaulting Small and Micro Enterprises from the Perspective of Multi-party Game, Prediction, 39 (02), 76, 2020.

19. ZHAO X., BAI Y., DING L., XUE Y. Evolutionary Game of Financing for Verification Emission Reduction Pledge with Government Participation, Journal of Beijing Institute of Technology (Social Science Edition), 22 (01), 29, 2020.

20. XIAO K., XU S., XIONG J. Mechanism and Path Dedication of Group Financing - Financing Decision and Rational Breakout of Small and Medium Enterprises Based on Game Analysis, Journal of Finance and Economics (05), 39, 2009.

21. HUANG H., LIU Q., YE C., CHEN X. Game Analysis of Government Procurement Contract Financing Based on Blockchain Technology, Journal of System Simulation (08), 1, 2020.

22. FANG L., XIA Y., YANG Y. Supply Chain Financing Decision Equilibrium Considering Retailers' Sales Efforts, Systems Engineering Theory \& Practice, 38 (01), 135, 2018.

23. ZHANG L., HU H., ZHANG D. Evolutionary Game Analysis of Accounts Receivable Pledge Financing Model, China Circulation Economy, 27 (06), 121, 2013.

24. ZHENG Z., BAO X. Research on the Inspection Rate and Punishment Mechanism of Accounts Receivable Financing in Supply Chain Finance, Economic Review (06), 149, 2014.

25. LU Q., ZENG L., BAO X. Supply Chain Procurement Financing Model Based on Stackelberg Game, Control and Decision, 29 (10), 1907, 2014.

26. WANG Z., TIAN X., CHEN X. A Game Analysis of Supply Chain Finance under Account Receivable Financing Model Considering Recessive Equity, Chinese Journal of Management Science, 23 (09), 1, 2015.

27. PENG H. Supply Chain Accounts Receivable Mortgage Financing Strategy with Uncertain Output, Journal of System Management, 25 (06), 1163, 2016.

28. CAO W., MA C. Game Analysis of Accounts Receivable Financing Based on Supply Chain Finance, Business Research, 3 (05), 168, 2013. 